\title{
EL ASOCIACIONISMO NEGRO EN CUBA: UNA VÍA DE INTEGRACIÓN EN LA SOCIEDAD REPUBLICANA (1920-1960)
}

POR

\author{
ELSA PIGNOT
}

Universidad del Franco Condado, Besançon

En la Cuba recién independizada el asociacionismo negro fue cobrando funciones particulares en este nuevo contexto republicano de la primera mitad del siglo XX. A partir del análisis especializado de dos sociedades negras de instrucción y recreo de la ciudad de Pinar del Rio, se observa cómo se convirtieron en considerables plataformas de integración social de sus miembros. Sin embargo esa meta, conforme con el imaginario nacional en construcción, implicaba una continuación del proceso de aculturación y de la heterogeneización de la población negra. Finalmente, estos dos espacios de sociabilidad fueron espejos del sistema jerárquico imperante en Cuba.

PALABRAS Clave: República cubana, asociacionismo negro, exclusión e integración, aculturación, imaginario nacional.

Podría parecer paradójica en la República cubana de 1902 la perduración e incluso la formación de asociaciones racialmente definidas veinte o treinta años después de que la Constitución cubana promulgara la igualdad entre todos los ciudadanos ${ }^{1}$. Persistía obviamente un desfase entre las bases constitucionales y la realidad social de Cuba. Desde principios del siglo se impuso un mito de igualdad duradero que arrojó silencio sobre la cuestión racial, disimulando los verdaderos problemas de racismo heredados de los tiempos coloniales ${ }^{2}$.

\footnotetext{
1 Pichardo Viñals, 1971: 77.
}

2 Helg, 2000: 146-148. 
Las sociedades negras se constituyeron en respuesta a la discriminación ejercida por los círculos sociales de ocio blancos, que le negaban el acceso a los negros. Pese a haber adoptado un funcionamiento próximo al blanco, el asociacionismo negro adquirió unas funciones muy particulares ${ }^{3}$. La principal fue la de contribuir a la integración de sus miembros en la nación en construcción, lo que se operaba tanto a nivel de su participación en la elaboración del imaginario nacional, como a nivel de su inserción en la sociedad cubana. Sin embargo, de la misma manera que resultaba problemática su asimilación de un ideario predominantemente blanco y excluyente, esas organizaciones conllevaban una paradoja interna: la de reproducir mecanismos de exclusión y de elitismo para alcanzar un lugar en el panorama social. La existencia de distintas asociaciones de este tipo en la misma ciudad, la selección de la membresía y la jerarquía interna de cada una reflejaban la propia jerarquización de la sociedad cubana.

A pesar de los grandes cambios sociales y políticos ocurridos a raíz de la abolición de la esclavitud, de las luchas independentistas y de la proclamación de la República, se nota una continuidad entre el pasado colonial y el período republicano por lo que atañe a la estructura jerárquica de Cuba. En su conformación siempre desempeñó un papel relevante el color de la piel. Aquel vínculo establecido entre la condición social y racial había penetrado en el imaginario colectivo con la esclavitud ${ }^{4}$, y siguió presente en las mentalidades a lo largo del siglo XX. Luego, numerosas sociedades negras republicanas tuvieron su origen en el asociacionismo colonial, en particular de finales del siglo XIX ${ }^{5}$. Tanto la criminalización y represión de las tradiciones africanas como el mantenimiento de los prejuicios raciales impulsaron a una clase incipiente a sociabilizarse creando sus propios círculos sociales. Por medio de aquéllos, esperaba alejarse de las imágenes peyorativas comúnmente aplicadas

3 Numerosas asociaciones blancas siguieron existiendo en la República, distinguiéndose todavía por el nombre de la región de España de que procedían sus fundadores (como el Centro Gallego o el Centro Asturiano). Sobre el asociacionismo, ver Barcia, 2005: 19-167. Montejo Arrachea, 2004: 135-279.

4 En la colonia, calificar de «negro» a cualquier esclavo procedente del continente africano contribuía a negar la diversidad de los orígenes étnicos de la mano de obra importada, iniciando un largo proceso de homogeneización y de aculturación para aquella parte poblacional de la Isla. No obstante, es notable que la Corona, interesada por mantener la división entre los esclavos, autorizó la reunión de «cabildos de nación», unos aparatos de transmisión cultural importantes hasta principios del siglo XX, que agrupaban a personas originarias de la misma región de África. García, 2004: 65-73.

${ }^{5}$ La progresiva liberación y emancipación de los esclavos posibilitó cada vez más su participación en diversos tipos de asociaciones, incluso a veces racialmente incluyentes. Casanovas Codina, 2000: 176-231. 
a las personas de piel oscura ${ }^{6}$, y demostrar su capacidad para integrarse en la sociedad civil emergente. En las últimas décadas del siglo XIX, los criterios de acceso a ciertas asociaciones ya reflejaban unas desigualdades crecientes entre esa población ahora libre ${ }^{7}$.

Si bien se emplea el término abarcador «negro» para designar a un conjunto poblacional cada vez más ecléctico en el siglo $\mathrm{XX}$, este estudio pretende contribuir a romper con la imagen errónea de un sector poblacional homogéneo y forzosamente solidario ${ }^{8}$. El hecho de haber adquirido el estatus de ciudadanos permitió a los negros diversificar sus posiciones sociales, aumentando correlativamente sus desigualdades. La evolución del mercado de trabajo y la alfabetización a lo largo de las primeras décadas republicanas demuestran ya en los años 1920 una elevación de nivel social en parte de la comunidad ${ }^{9}$. En La Habana por ejemplo, ese ascenso se tradujo a través de la fundación del Club Atenas, círculo de color elitista cuyo prestigio representó un modelo a seguir para otras asociaciones de la Isla $^{10}$. La década revolucionaria de 1930 también acarreó cambios significativos en la percepción de la población negra en Cuba. Mientras se debatía una definición de la cultura cubana que tomara en cuenta todos sus componentes étnicos, se iban fundando nuevos clubes portadores de ideas igualitarias ${ }^{11}$. El acceso creciente de los negros a diversos espacios de expresión, ya fueran políticos, intelectuales o asociativos, no sólo les permitió ganarestima y derechos ${ }^{12}$, sino que también aceleró su proceso de he-

${ }^{6}$ Helg, A., 2000: 125-161. Naranjo Orovio, 20 (Madrid, 1998): 231-232; 16 (Río Piedras, Puerto Rico, 2005): 137-179; 19 (Praga, 2007): 313-325.

7 Scott, 2001. Existían sociedades que sólo reclutaban a «pardos», como era el caso de la Sociedad El Adelanto en Pinar del Río. Ver Helg, 2000: 41.

${ }^{8}$ Frente al profuso vocabulario elaborado en la colonia para distinguir a las personas según la pigmentación de su piel, este artículo sólo recurre a determinados matices en referencia al lenguaje de los propios actores de la época (negro/mulato por ejemplo). En cuanto a «negro», se emplea por su fuerte contenido histórico e identitario, ya que eludirlo sería alimentar el olvido de toda la discriminación ejercida hasta hoy en día. Ver cuestiones terminológicas en Scott, 2001: 30-31. Ortiz, 1975.

9 Fuente, 2000: 168, 205, 219 (tablas).

10 Fundado en 1917, el Club Atenas publicó su propia revista a partir de 1920: Atenas: Revista mensual ilustrada de afirmación cubana: órgano oficial del Club Atenas.

11 Fuente, 2000: 252-264, 281-284. Estas páginas enfocan respectivamente el movimiento afrocubanista y dos organizaciones: el Directorio Social Revolucionario «Renacimiento» y el club Adelante (surgidas después de la caída del presidente Gerardo Machado en 1933). También se destacaron en ese período los debates suscitados por intelectuales afrocubanos a través de la prensa (ver Gustavo Urrutia), así que a través de la poesía negrista (ver Nicolás Guillén).

12 Tan sólo fue en 1940 cuando se logró la inclusión en la nueva Constitución de una ley en contra de la discriminación racial, pero las presuntas leyes complementarias que permitiesen su aplicación efectiva aún seguirían nutriendo ilusiones durante mucho tiempo. En esas reivin- 
terogeneización. Reflejos de este fenómeno, sus organizaciones, persiguiendo siempre la aceptación de sus miembros en la sociedad cubana, también fomentaron cierta disparidad, y continuaron el proceso de aculturación por su identificación con la cultura blanca hegemónica, ambigüedades que se pueden observar en dos sociedades negras de la ciudad de Pinar del Río: Atenas Occidental (AO) e Hijos de Maceo (HM) ${ }^{13}$. La investigación que se llevó a cabo sobre estos dos espacios de sociabilidad adoptó una perspectiva local para acceder a una serie de informaciones prosopográficas enriquecedoras del tema. Fueron extraídas de distintos tipos de fuentes, ya fuera de los archivos pinareños (en particular de la prensa local de la época), de los propios órganos y documentos de esas asociaciones hoy en día desaparecidas, o de las entrevistas realizadas con un número apreciable de antiguos $\operatorname{socios}^{14}$. Del conjunto de todas las fuentes se ha llegado a constituir unos bancos de datos muy útiles para el análisis de ambas instituciones, desembocando en una mejor comprensión del grado de contribución del asociacionismo negro republicano a la formación e integración de los ciudadanos de piel oscura, tanto dentro de su propia comunidad, como en la nación recién nacida.

\section{INTEGRACIÓN SIMBÓLICA: LAS SOCIEDADES Y EL IMAGINARIO NACIONAL}

El análisis de las Sociedades AO e HM revela sus esfuerzos por contrarrestar el rechazo de la población negra generado por la sociedad cubana. El alcan-

dicaciones desempeñó un papel significante la Federación Nacional de Sociedades Cubanas (FNSC), fundada en 1936 bajo la apelación de Federación Nacional de Sociedades Negras. Montejo Arrachea, 2004: 227-246.

13 La Sociedad AO se fundó en 1920. Ver «Atenas Occidental celebró el XXIX aniversario de su fundación con una gran velada», XXVI / 1990 (Pinar del Río, 26 de marzo de 1949), Archivo Provincial de Pinar del Río (APPR). Un antiguo carnet de identificación de socio fundador (Sandalio Llinás) de 1919, facilitado por una antigua socia de AO (Julieta Carrillo), muestra que la sociedad se había formado antes. En cuanto a HM, se fundó en 1936. Ver Reglamento de la Sociedad «Hijos de Maceo», 17 de octubre de 1952, facilitado por Santos Carrete Galán, Pinar del Río: 1. Por fin, la fecha del cierre de ambos círculos sociales, según varios testimonios orales y documentos oficiales facilitados por antiguos miembros, correspondería con la fecha oficial del cierre de todas las asociaciones de ese tipo en Cuba por la implantación del régimen revolucionario de 1959: 1961. Ver Espina Prieto y Rodríguez Ruiz, 45 (La Habana, enero-marzo de 2006): 45.

14 A partir de una guía elaborada al efecto, grabé entrevistas en Pinar del Río (y en La Habana) con 30 personas entre noviembre de 2007 y mayo de 2008. Éstas también facilitaron algunos documentos que habían conservado sobre AO e HM, como invitaciones, fotografías, e incluso actas oficiales. Les agradezco mucho su amabilidad y su aporte fundamental para la investigación. 
ce de ese reconocimiento tan anhelado por la mayoría de sus miembros iba pareja con una integración simbólica. No se trataba meramente de aceptar un conjunto de imágenes aún excluyente, sino de contribuir a su evolución intentando cambiar el lugar de la población negra en él, o más bien su ausencia.

Todas las sociedades anteriormente esclavistas guardaron fuertes huellas de su pasado. Pero en Cuba, la marca indeleble del color de la piel respaldó los estigmas y la vergüenza vinculados a la clase antiguamente esclava y actuó en contra de su debida participación social, política y económica ${ }^{15}$. A pesar de la Constitución de 1901, los negros siguieron siendo los ciudadanos más despreciados en el sector laboral ${ }^{16}$, así como en los espacios de ocio, tanto públicos como privados. Las tardías fundaciones de AO y de HM fueron testigas de la permanencia de la exclusión en la ciudad de Pinar del Río, donde igualmente se encontraban dos lugares de reunión blancos: el Liceo y la Colonia Españo$1 a^{17}$. Varios antiguos socios entrevistados evocaron la discriminación que existía en la esfera educacional. Si bien no faltaban negros para hacerse maestros, a menudo los únicos puestos que obtenían eran como suplentes o se hallaban alejados de la ciudad. Este testimonio de una antigua docente lo expresa:

Había muchos maestros en Atenas Occidental porque la escuela era gratuita, pero muchos no tenían trabajo ${ }^{18}$.

Ahora bien, la muy escasa presencia de las personas de piel oscura en el imaginario nacional de principios del siglo XX se debió a varios factores que vinieron a consolidar los prejuicios imperantes desde la época colonial. En el curso del siglo XIX, la fuerza demográfica y las repetidas insurrecciones de los negros $^{19}$ empezaron a preocupar a las elites dirigentes, que desde la revolución de Haití venían nutriendo el llamado «miedo al negro» ${ }^{20}$. Se empezó a discutir los

15 Tocqueville, 1990: 261-262.

16 Su representación en los estratos más bajos de la sociedad cubana era importante, y muchos desempeñaban los mismos oficios que les eran tradicionalmente reservados (trabajos de limpieza, trabajos manuales, etc.).

17 Sus actividades eran reseñadas por la prensa local, disponible y consultada en el APPR.

18 Carrete Galán, Hilda, AO, 22 de mayo de 2008. Ver también López, Julio, AO, 3 de mayo de 2008. En el artículo siguiente se reseñaba la denuncia por un delegado pinareño de la discriminación racial en la provincia: «La Convención de Sociedades de Color», III / 55 (La Habana, 14 de febrero de 1938): 13, Biblioteca Nacional José Martí (BNJM).

19 Le Riverend Brusone, 1985: 321. Según el autor, la población de color había incrementado hasta representar un 58\% de la población total de Cuba en 1841 (blancos: 42\%; libres de color: 15\%; esclavos: 43\%). Sobre las revueltas, ver García, 2003. Barcia Paz, 1998. Franco, 2006.

20 El temor a que los negros conspirasen en contra de los intereses de los blancos fue jalonando la historia decimonónica cubana desde la revolución haitiana de 1791, y resurgió en va- 
medios adecuados para controlar a aquel sector de la población, proyectando políticas de inmigración favorecida destinadas a blanquear al pueblo cubano y a eliminar a largo plazo la negrura en $\mathrm{Cuba}^{21}$. Pese a la participación activa de los negros en las luchas independentistas, la perduración de tales mecanismos racistas durante la República dificultó su inclusión en el proyecto patrio.

Otra influencia procedió de los Estados Unidos, los cuales iniciaron políticas de saneamiento vehículos de esos prejuicios durante sus dos ocupaciones de la Isla (1898-1902 y 1906-1909)22. Luego, el desarrollo en el mundo de algunas teorías de determinismo racial también marcó el pensamiento científico cubano de principios del siglo $\mathrm{XX}^{23}$. Las explicaciones antropométricas, biológicas, criminales, o aun médicas que se elaboraron sobre la inferioridad de la «raza negra» legitimaban los estereotipos negativos que solían aplicarse todavía a ella, así como el escaso espacio que le era conferido en el país ${ }^{24}$. Se justificaba asimismo la persecución oficial de la «brujería», asignando a las tradiciones afrocubanas (como la santería) un carácter peligroso para el bienestar público ${ }^{25}$.

Sólo a partir de los años 1920 cambiaron de tono esas tesis, en particular en el antropólogo Fernando Ortiz, quien ahora privilegiaba el concepto de cultura en detrimento del de «raza» ${ }^{26}$. Al mismo tiempo comenzó a brotar una clase media en la población negra, fenómeno con el cual coincidió la fundación de AO en Pinar del Río, como eco a la aparición de importantes sociedades homólogas en la capital del país ${ }^{27}$. Más tarde, con el movimiento afrocubanista de la década de 1930 en trasfondo, se fundó en Pinar del Río la Sociedad HM, representante pues de otra generación y portadora de nuevos ideales. A pesar de esa innegable progresión, la discriminación aún se manifestaba de manera muy concreta en la

rias ocasiones en la República. Naranjo Orovio, 19 (Praga, 2007): 313-325. Helg, 2000: 217-220. González Ripoll, Naranjo, Ferrer, García y Opatrny, 2004.

21 Naranjo Orovio, 25 (Santiago de Cuba, 1996): 54-62.

22 Helg, 2000: 125-161. La dependencia de Cuba a Estados Unidos fue determinada por la Enmienda Platt en 1901. Ver Pichardo Viñals, 1971, TII: 118-120.

23 Se nota su influencia en los trabajos de algunos antropólogos cubanos, como Israel Castellanos e incluso Fernando Ortiz en su primer período. Naranjo Orovio y Puig-Samper, VII / 13 (La Habana, 2006): 53-66. Ortiz, 1916.

24 Naranjo Orovio, 25 (Santiago de Cuba, 1996): 54-56.

25 En particular, se alzaron acusaciones en contra de la Sociedad secreta Abakúa, cuyos miembros (los «ñañigos»), fueron tenidos muchas veces por responsables de desapariciones y hasta de sacrificios de niños blancos. Naranjo Orovio, 19 (Praga, 2007): 317.

26 Ortiz, 1975. Naranjo Orovio, Extra 5 (2004). Naranjo Orovio y Puig-Samper Mulero, LX / 219 (Madrid, 2000): 477-503. Ortiz García, LXIII / 229 (Madrid, 2003): 695-736. Puig-Samper y Naranjo Orovio, Naranjo Orovio y Serrano (Eds.), 1999: 197-226.

27 Si bien existían numerosos tipos de sociedades negras en La Habana, las más prestigiosas en la República fueron el ya mencionado Club Atenas, y la Unión Fraternal. 
vida cotidiana y se encontraba implícita en la cultura nacional. Por cierto, se iba plasmando dentro de la población de color una distinción interna, basada muchas veces en un entrelazamiento de criterios sociales y raciales. En resumidas cuentas, el asociacionismo no sólo constituyó un espejo de la imperfección de la igualdad en Cuba, sino que también la fue reproduciendo.

Efectivamente, AO e HM participaron en la elaboración de un imaginario que si bien enarbolaba la igualdad como garante de unidad nacional ${ }^{28}$, perpetuaba estereotipos grandes. Cada objetivo contenido en la divisa de la Sociedad HM tendía a conformar a sus adherentes con esas representaciones hegemónicas del cubano, y llevaba ya todas las contradicciones señaladas:

Moralidad, progreso, regeneración de nuestros elementos, y unión fraternal entre todos los habitantes del país ${ }^{29}$.

En primer lugar, AO e HM reforzaron la idea de integridad patriótica destacando un pasado y unos héroes comunes con los demás cubanos. Conmemoraban varias fechas simbólicas al año ${ }^{30}$, y ciertos artículos escritos por socios de AO también recordaban la lucha por la independencia de todos los habitantes de Cuba, ya fueran de piel clara u oscura:

Atenas Occidental por encima de nuestras pasiones y sólo Cuba por encima de Atenas Occidental, dada la mucha sangre negra que amasó los cimientos de nuestra nacionalidad ${ }^{31}$.

En sus referencias a los héroes nacionales, hacían hincapié en la posición que éstos arbolaban respecto de la cuestión racial. Las dos figuras más citadas eran por supuesto José Martí y Antonio $\mathrm{Maceo}^{32}$. Ambos creían en la fraternidad en las filas insurrectas y daban prioridad a la idea de nación sobre la de ra$\mathrm{za}^{33}$. Pero si bien ese nacionalismo llevó una oposición al racismo, su manipu-

28 Sobre los procesos de reconciliación necesarios para la formación de una nación, ver Renan, 2007.

29 Reglamento de la Sociedad «Hijos de Maceo», 17 de octubre de 1952, facilitado por Santos Carrete Galán, Pinar del Río.

30 Esas conmemoraciones se reseñaban en los periódicos locales Heraldo Pinareño y Vocero Occidental, y fueron mencionadas por la mayoría de los antiguos socios entrevistados.

31 «Del Presidente de «Atenas Occidental» a nuestro director», XVI / 959 (Pinar del Río, 4 de enero de 1938): 1, APPR.

32 Pichardo, 1971, TI: 394-400 (cartas de Maceo en las que expuso su antirracismo). Sin embargo, la aceptación del «Titán de Bronce» (A. Maceo) por parte de las élites blancas como héroe de la guerra independentista no fue tan evidente. En 1900, una comisión nacional realizó estudios antropológicos sobre su cráneo para probar que su herencia blanca fuese preeminente. Helg, 2000: 145-147.

33 En el artículo siguiente, el «Padre de la Patria» negaba la posibilidad de que existiese racismo por no creer en la existencia de razas: Martí, 1975: 15-23. 
lación en el siglo XX le otorgó otra resonancia. Al proclamar la inexistencia de las razas para reforzar el sentimiento patriótico, se borraba al mismo tiempo las diferencias culturales, y se negaba que pudiera existir racismo, aun cuando su expresión era patente en muchos terrenos. En el mismo sentido se puede citar el fragmento de artículo siguiente:

Cuba, que no puede ser racista por razones de historia y de familia $[\ldots]^{34}$

Por esta afirmación, el socio de AO citado concurría al sostenimiento del mito de igualdad ya evocado, ubicándose en perfecta armonía con el ideario predominante.

En segundo lugar, $\mathrm{AO}$ e $\mathrm{HM}$ defendieron valores progresistas, como que los negros necesitaban ser instruidos para igualar a sus conciudadanos blancos y merecer su estima ${ }^{35}$. Si bien esa idea enfocaba otra vez la necesidad de integración, continuaba sugiriendo la falta de educación y de civilización, aferrada desde hacía mucho tiempo en las mentalidades. En este sentido, resulta interesante establecer un paralelo entre las opiniones de AO e HM y la del Senador mulato Martín Morúa Delgado ${ }^{36}$. Para éste, la superación de la discriminación racial debía pasar por una desaparición de las diferencias, y el negro debía esforzarse por demostrar sus capacidades e incorporarse a las instituciones preexistentes. Con la propuesta de su enmienda ${ }^{37}$, se oponía a la política del Partido Independiente de Color (PIC), el cual era partidario de una lucha colectiva y reivindicatoria ${ }^{38}$. Fuera por temor a la represión o por convicción, numerosas sociedades negras

34 Herrera Quintáns, 2 (Pinar del Río, 15 de febrero de 1933): 8. La famosa declaración de Antonio Maceo iba en el mismo sentido: «Ni blanquitos ni negritos, sino cubanos». Ferrer, 24-25 (La Habana, 2002): 21.

35 Ya defendían esta idea ciertos intelectuales blancos como Enrique José Varona a finales del siglo XIX.

36 El mulato Martín Morúa Delgado (de padre vasco y de madre esclava) nació libre, se hizo masón y dedicó mucho tiempo de su vida a la política. De autonomista, pasó a ser independentista durante las últimas luchas del siglo XIX, y participó en la Asamblea Constituyente en 1900. Como senador, propuso proyectos democráticos y progresistas que raras veces se realizaron. $\mathrm{Mu}-$ rió en 1910, unos meses después de la aprobación de su enmienda. Ver Soucy, 2006.

37 Pichardo Viñals, 1971, TII: 364. Aprobada en febrero de 1910, la llamada Enmienda Morúa prohibió la formación de agrupaciones políticas o independientes racialmente excluyentes, y desató una polémica considerable. Ya a finales del siglo XIX, al cobrar importancia el Directorio Central de Sociedades Negras (dirigido principalmente por Juan Gualberto Gómez), Martín Morúa Delgado había condenado la empresa. Ver Hevia Lanier, 1996.

38 Creado en 1908, el PIC fue tachado a veces de antipatriótico y de racista, cuando lo que defendía era precisamente la igualdad. Despertó nuevos rumores sobre una conspiración negra, y tanto el debate político como los estereotipos nuevamente expuestos por la prensa terminaron formando un estado de alarma en la Isla. En 1912, el movimiento se acabó en una matanza erróneamente denominada «guerra de razas». Ver Helg, 2000. Portuondo Linares, 2002. 
adoptaron entonces una actitud distante con respecto al PIC, y hasta lo condenaron. El nivel social de los miembros de aquellas asociaciones también podía explicar el desfase ideológico entre ellas y los independientes de color, en su mayoría procedentes de capas populares. Aunque AO e HM no presenciaron aquellos acontecimientos, su ideología fue necesariamente influenciada por sus repercusiones. En efecto, optaron por animar la integración personal de sus socios tanto en el imaginario nacional como en la sociedad pinareña.

En último lugar, su estrategia para conseguir lo antedicho recurría a un mimetismo de la cultura más difundida en Cuba: la blanca. Los valores inculcados por ambas sociedades pinareñas estaban destinados a alejar a sus miembros de los tópicos del negro bárbaro, delincuente o brujo, a fin de frenar su apartamiento. No obstante, la opción escogida no fue valorizar los rasgos culturales africanos despreciados hasta entonces, sino renegar de ellos para asimilar la cultura «nacional». De hecho, ese proceso de aculturación se expresaba en diversas actividades culturales y sociales de AO e HM.

\section{INTEGRACION SOCIAL: UNOS ESPACIOS DE SOCIABILIDAD EDUCATIVOS}

La integración simbólica en la nación cubana perseguida y lograda en cierta medida por las Sociedades AO e HM se plasmaba por una búsqueda de la integración cultural, social y política de sus miembros.

Desde un punto de vista cultural, AO e HM se distanciaron de las tradiciones de la parte africana de su herencia, y abrazaron una cultura occidental, blanca y hegemónica. Efectivamente, todos los socios entrevistados a propósito de la cuestión religiosa en las Sociedades AO e HM negaron rotundamente que se practicara en ellas santería u otras religiones afrocubanas. Aunque no era descartada la posibilidad de que alguien las practicara en privado, siempre se subrayaba que ese asunto no tenía nada que ver con la sociedad, y ningún antiguo socio se extendió sobre el tema. Otra vez, esa actitud estaba conforme con el rechazo de esas religiones por las clases influyentes de Cuba. En cambio, y a pesar de que tampoco se producían manifestaciones católicas en los locales asociativos, varios antiguos socios declararon que eran católicos. El testimonio siguiente revela los límites tanto culturales como sociales que se imponían entonces a los negros:

Los socios en general iban a la iglesia, porque era una de las únicas cosas que había: ir a la iglesia, ir a la sociedad. ¿A dónde más ibas a ir? No tenías otra opción ${ }^{39}$.

39 Viruliche, Emilia, HM, 29 de enero de 2008. 
Luego, la «buena» educación necesaria para ingresar en AO y en HM y sus exigencias acerca de la conducta que debían observar los socios, revelaban la imitación de unos modos y valores culturales blancos. Para participar en las diversas actividades recreativas organizadas por las sociedades, se valorizaba el refinamiento, la decencia, y «la moral era sagrada ${ }^{40}$. En particular, se podía observar en los bailes de AO una indumentaria típicamente blanca. De ninguna manera se venía vestido con traje africano, y según los entrevistados, las mujeres lucían elegantes vestidos largos y los hombres trajes con corbata ${ }^{41}$.

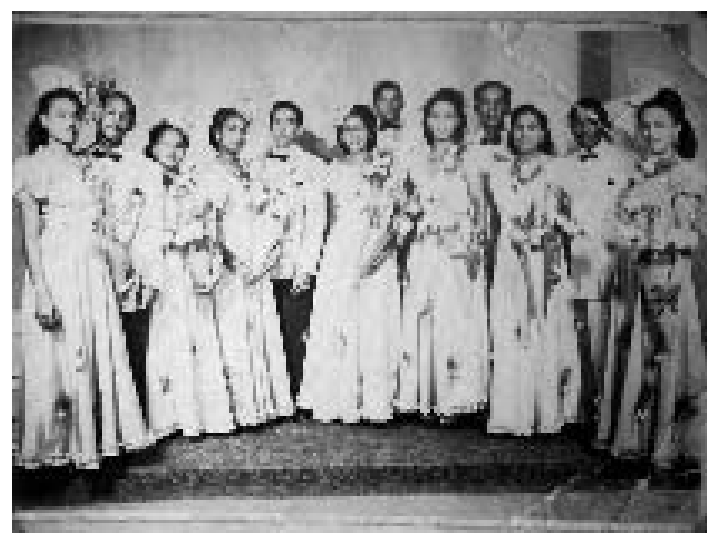

Julieta Carrillo subrayaba en su testimonio la importancia del respeto entre los socios y de las pautas de conducta durante las fiestas bailables. Su hijo lo interpretó contraponiendo la época en que existían sociedades negras en Cuba con la época post-revolucionaria contemporánea:

Estas sociedades crearon una disciplina social. Y eso era un mérito que tenían [...] Pero desde el punto de vista social, de educación, de respeto, eso se perdió [...] esta igualdad trajo como contraste que se perdieron muchos valores éticos ${ }^{42}$.

La instrucción de los socios también era fomentada por la organización de otras actividades culturales como veladas artísticas y literarias en que se canta-

40 Vázquez Rodríguez, Gilberto («Filo»), AO, 18 de marzo de 2008.

41 Esta fotografía representa a unas parejas de AO listas para una comparsa, y fue facilitada por Hilda Carrete Galán. Entre las variadas fotografías enseñadas por los entrevistados (veladas culturales, directivas, bailes, etc.), aun las de carnavales muestran unos disfraces occidentales. Una antigua socia de AO comentó que «no eran comparsas de bailar por la calle, sino una música bonita, pero muy elegante», diferenciándolas de las comparsas populares tradicionalmente celebradas por los negros con bailes africanos y tambores. Gómez, Yolanda, AO, 10 de diciembre de 2007.

42 Carrillo, Julieta y Llinás Carrillo, Sergio, AO, mayo de 2008. 
ba, se tocaba o se leía poesía. En HM, se organizaba cursos de corte y costura o de artesanía para quien estuviese interesado ${ }^{43}$. En cuanto a $\mathrm{AO}$, en ocasiones proyectaba películas o programaba conferencias con intervinientes exteriores, y un grupo se encargaba de la redacción de una revista ${ }^{44}$. En todas esas manifestaciones culturales se vislumbraba el deseo de integración de los socios en la cultura cubana, cuya mayor base aún era la cultura blanca.

Ahora bien, las Sociedades AO e HM no sólo reproducían unos modos de vida próximos a los blancos, sino que también se inclinaban hacia una cultura propia de las clases medias o burguesas. La familia ocupaba un lugar importante en ambas sociedades, aunque con implicaciones diferentes. Entre los numerosos comentarios de los antiguos socios al respecto, se puede citar el siguiente:

Había respeto a la familia, al apellido ${ }^{45}$.

Resulta interesante relacionar ese énfasis con el reproche muy corriente que se les hacía a los negros, el de mantener relaciones irregulares y de provocar deseos indecorosos. Todo lo contrario, AO e HM ensalzaban la familia, la moral y el matrimonio ${ }^{46}$. En resumidas cuentas, defendían los mismos valores conservadores que las clases blancas influyentes.

Al mismo tiempo, se autoproclamaban progresistas, es decir que de algún modo admitían la necesidad de progresión para formar parte de la sociedad cubana, y creían en la posibilidad de regeneración de la «raza negra». En un artículo publicado en la revista Evolución, titulado «Renovarse o morir», un socio de AO expresaba su opinión sobre los fines que las sociedades negras deberían llenar:

[...] esas sociedades no han logrado hasta el presente iniciar la modificación de la estructura espiritual del hombre negro ${ }^{47}$.

Los miembros de AO e HM no sólo tenían el objetivo de igualar a los blancos en derechos, sino también en reconocimiento social. Sus homólogas blan-

43 Emilia Viruliche recordaba haber entrado en HM antes de la edad mínima reglamentaria (15 años), con 13 años, justamente para asistir a cursos de corte y costura. Viruliche, Emilia, HM, 17 de marzo de 2008.

44 Se consultó números de las revistas de AO: Evolución (1924), Batuala (1933) y Atalaya (1942). Según Germán Ferrer, la revista Atalaya todavía se publicaba a finales de los años 1950. Algunos testimonios y balances periodísticos dejan pensar que pudo haber otras revistas que desgraciadamente se perdieron. Ferrer Casanova, Justo Germán, AO, 23 de mayo de 2008.

45 Carrete Galán, Hilda, AO, 22 de mayo de 2008.

46 En artículos de las revistas de AO se percibía por ejemplo el papel tradicional que era reservado a la mujer como «reina del hogar». Batuala, 2 (Pinar del Río, 15 de febrero de 1933): 4 у 7.

47 Pozo, II / 9 (Pinar del Río, octubre de 1924): 8. 
cas muchas veces representaban un modelo, o por lo menos una fuente de admiración. Por ejemplo, Julieta Carrillo evocaba el baile de la sociedad blanca para el último día de la fiesta de la Candelaria en Consolación del Sur:

Nosotras íbamos al parque para ver entrar a la sociedad de blancos a los que iban, iporque eran unos trajes! Nosotras también íbamos [a nuestra sociedad], pero bueno, ellos iban elegantísimos. El baile social era un baile de lujo ${ }^{48}$.

El mismo deseo de aproximarse al nivel de la población blanca se aprecia en el testimonio de Yolanda Gómez, quien definía a la membresía de AO de la forma siguiente:

Había miembros negros, mulatos, y miembros casi de piel blanca ${ }^{49}$.

En suma, la educación cultural y la valorización de los socios de AO y de HM contribuían a su aceptación en Pinar del Río y los acercaba cada vez más al ideal cubano promovido por los sectores influyentes de la época.

Luego, la propia organización de las Sociedades AO e HM representaba su grado de integración social. En ambas, los miembros elegían por medio de elecciones una junta directiva, que contaba con un presidente, un secretario, un tesorero, sus respectivos vices, y vocales. Se celebraban reuniones con frecuencia para planificar actividades ${ }^{50}$. Este funcionamiento no les era exclusivo, puesto que se observa una estructura asociativa similar tanto en las demás sociedades negras de Cuba (desde el Club Atenas hasta la Sociedad El Porvenir, de Consolación del Sur), como en las sociedades blancas. Además, esa organización interna se avecinaba en algunos aspectos a la organización democrática pero jerarquizada del propio aparato estatal. Finalmente, como microsociedades, $\mathrm{AO}$ e $\mathrm{HM}$ ofrecieron un aprendizaje cívico a sus miembros.

Fueron múltiples las redes sociales que desarrollaron, directa o indirectamente, y que favorecieron desde luego la integración de sus participantes en la ciudad. Esa función fue subrayada en 1946 en un discurso pronunciado en honor del antiguo presidente de la Federación Provincial de Pinar del Río (Narciso López):

Así se vería la alta función social de todas estas instituciones, que en el orden de progreso harían una labor sociabilizadora ${ }^{51}$.

48 Carrillo, Julieta, AO, 23 de enero de 2008 (aquí se refiere al período en que vivía en el pueblo de Consolación del Sur y era socia de la Sociedad El Porvenir).

49 Gómez, Yolanda, AO, 10 de diciembre de 2007.

50 Esas informaciones proceden de varios tipos de fuentes: Reglamento de la Sociedad $H M$, testimonios orales, artículos locales que anunciaban cada año los nombramientos de la nueva directiva, y documentos facilitados por antiguos socios.

51 «Ecos de un homenaje», (Pinar del Río, junio de 1946): 3 y 6, Biblioteca Provincial de Pinar del Río (BPPR). 
De hecho, AO e HM multiplicaron los intercambios con diversas sociedades negras de la provincia, y a veces de otras partes de la isla ${ }^{52}$. Igualmente mantenían contactos regulares con los poderes locales de Pinar del Río, y colaboraban en eventos de la ciudad conjuntamente con otras instituciones pinareñas. Su patriotismo y fe en la República, traducidos en conmemoraciones en sus locales, también podían expresarse de forma pública ${ }^{53}$. Las fiestas organizadas por la municipalidad suscitaban a veces la reunión de todas las instituciones de Pinar del Río. En los carnavales por ejemplo, todas las sociedades (tanto negras como blancas) sacaban su carroza por la calle y hacían un recorrido, pero luego cada una daba un baile en sus propios salones ${ }^{54}$. Incluso algunos antiguos socios recordaron que en ocasiones se producían intercambios entre los socios directivos de las sociedades negras y blancas de la ciudad ${ }^{55}$.

A nivel personal, los miembros de AO y de HM solían pertenecer a varios círculos sociales fuera de ese compromiso asociativo. Podían ser colegios profesionales, logias masónicas o partidos políticos. Se puede citar a Armando Díaz Bravo, quien perteneció a ambas sociedades negras de Pinar del Río, fue profesor, masón, delegado del partido demócrata, y miembro de una asociación local (fundada principalmente por médicos blancos para defender las condiciones de salubridad de la ciudad): el Comité «Todo por Pinar del Río» ${ }^{56}$.

Por último, ciertos socios participaban activamente en luchas políticas $^{57}$. Sin embargo, AO e HM se declaraban apolíticas en el sentido de que

52 Todos los entrevistados lo señalaron. Santos Carrete y Lilia Pérez (su mujer) incluso facilitaron invitaciones procedentes de otras asociaciones provinciales. Los contactos se desarrollaron en particular con La Habana, por las asambleas de la FNSC. Se dispone de varios tipos de fuentes sobre la participación de AO y de HM en la FNSC: expedientes del Registro de Asociaciones del Archivo Nacional de Cuba (ANC); artículos de periódicos locales; testimonios orales e invitaciones a congresos facilitados por antiguos miembros de $\mathrm{AO}$ y de $\mathrm{HM}$ que fueron delegados.

53 «Los actos del día 24 de febrero», V / 267 (Pinar del Río, 26 de febrero de 1927): en portada, APPR. «La visita del presidente de la República a esta ciudad constituirá un acontecimiento», V / 276 (Pinar del Río, 24 de marzo de 1927): 1, APPR.

54 Rubalcaba, Zoila, AO, 18 y 20 de marzo de 2008. Carrillo, Julieta, AO, 23 de enero de 2008.

55 Santos Carrete (antiguo presidente de HM) recordó haber visitado en determinadas ocasiones las Sociedades el Liceo y la Colonia Española, y haber recibido a su vez a miembros directivos de éstas en HM. Carrete, Santos y Pérez, Lilia, HM y AO, 20 de mayo de 2008.

56 Atalaya, I / 3 (Pinar del Río, 22 de abril de 1942). Heraldo Pinareño (Pinar del Río, enero de 1940 y enero de 1945). Vocero Occidental (Pinar del Río, enero y diciembre de 1943, marzo y octubre de 1955, enero de 1956). Pinar del Río (Pinar del Río, junio de 1947).

57 Por ejemplo, la más antigua socia de AO entrevistada (con 104 años) señaló que su marido (Alberto Chirino) estuvo comprometido con los comunistas entonces perseguidos por el 
no representaban oficialmente los intereses de ningún partido. El Reglamento de HM estipulaba:

La sociedad será ajena a toda idea política o de partido político ${ }^{58}$.

Varios antiguos socios lo confirmaron, como por ejemplo Germán Ferrer, quien era socio directivo de $\mathrm{AO}$ durante la dictadura de Batista:

La política no se llevaba allí. Cada uno tenía su negocio, pero era más personal que comunitario ${ }^{59}$.

En ese distanciamiento de lo político se puede leer una desilusión por la ineficacia del Estado en satisfacer sus expectativas. Pero el carácter personal de su compromiso político recuerda sobre todo la política de integración personal promocionada por Martín Morúa Delgado, y el reforzamiento del temor a la represión de luchas colectivas desde 1912. Además, cabe matizar esas afirmaciones señalando la interdependencia de las relaciones establecidas entre los poderes estatales y los organismos asociativos negros, representantes de un electorado notable y a veces influyente ${ }^{60}$. En este sentido, resulta significativa la anécdota contada por una antigua socia de HM sobre la visita de un candidato a la presidencia de la República (Carlos Saladrigas), quien había ofrecido un piano a la Sociedad $\mathrm{HM}^{61}$.

Al fin y al cabo, a pesar del carácter puntual de sus contactos con el mundo social predominantemente blanco, $\mathrm{AO}$ e $\mathrm{HM}$ no se rodearon con fronteras herméticas. Ya fuera por la educación o por la sociabilización de sus miembros, facilitaron su integración en la sociedad cubana. Ahora bien, pese a su proximidad, las dos sociedades negras de Pinar del Río no tenían los mismos criterios de acceso, y no dejaban de distinguirse en varios aspectos. Por cierto, su mimetismo respectodel mundo blanco llegaba hasta reproducir el esquema ya

gobierno, lo cual fue confirmado por algunos artículos de la prensa local que indicaron su militancia en el Partido Comunista. Valdés, Amparo («La Chinita»), Chirino Valdés, Margot (su hija) y «Filo», HM y AO, 19 de marzo de 2008. En la prensa local también se cita nombres de socios por su adhesión a diferentes partidos políticos.

58 Reglamento de la Sociedad HM: 1.

59 Ferrer, Germán, AO, 23 de mayo de 2008.

60 La estrategia de la FNSC en su lucha contra la discriminación racial reflejaba ese fenómeno. En las décadas de 1940 y sobre todo de 1950, la FNSC y el Estado desarrollaron unos vínculos cada vez más estrechos, motivados por sus intereses respectivos. Por un lado, permitieron a la Federación ganarse algunas ventajas pero por otro, la debilitaron e incluso acabaron provocando su escisión.

61 Monterrey Hernández, Mercedes («Mercedita»), HM, 20 de marzo de 2008. Ver también el artículo «\$ 42.000 distribuyó la renta de Lotería Nacional. Distintas sociedades e instituciones fueron beneficiadas», X / 410 (Pinar del Río, 3 de marzo de 1951). 
existente de las dos sociedades blancas de la ciudad, representantes cada una de clases sociales diferentes ${ }^{62}$.

\section{LA JERARQUIZACIÓN DEL ASOCIACIONISMO NEGRO PINAREÑO}

A la luz de la realidad social, no es sorprendente que el primer objetivo de los miembros de AO y de HM fuera elevar su autoestima y ser reconocidos por su entorno. En este sentido, se puede citar el testimonio de Germán Ferrer:

Que uno fuera de nivel alto, medio o bajo, en cualquier caso buscaba el respeto y el reconocimiento al entrar en la Sociedad Atenas Occidental ${ }^{63}$.

Si bien las Sociedades AO e HM tenían como principal función la de ayudar a la integración de sus adheridos tanto en el imaginario nacional como en la sociedad cubana, no la cumplían para cualquier ciudadano negro de la ciudad. Su acceso era restringido, puesto que para entrar era necesario corresponder con unos criterios evaluados por la directiva y poder pagar una cuota mensual, lujo que no todas las familias podían permitirse. En consecuencia, la pertenencia a una sociedad reflejaba cierto nivel social, ofrecía la posibilidad de alcanzar algún renombre, y de alejarse de las ya evocadas imágenes negativas asimiladas con el negro. De alguna manera, las Sociedades AO e HM marcaron y ahondaron las desigualdades entre los miembros de la comunidad negra republicana para lograr una mejor inserción en la sociedad. Pero esta función no se cumplía en la misma medida según se pertenecía a la una o a la otra. El análisis prosopográfico y comparativo del conjunto de las fuentes consultadas permitió entender la naturaleza de las diferencias entre ambas y desveló una jerarquía que no sólo existía entre socios de AO y de HM, sino también entre personas pertenecientes a la misma sociedad ${ }^{64}$. Por fin, la igualdad perseguida no se traducía en igualitarismo, ya que su búsqueda pasaba por el camino de una distinción social aún muchas veces vinculada con el color de la piel.

Primero, la clasificación en grandes categorías socioprofesionales de los miembros y su comparación según la sociedad de procedencia, indicaron una diferencia de nivel entre las membresías de ambas asociaciones ${ }^{65}$. En el gráfi-

62 El Liceo era más elitista que la Colonia Española, la cual acogía a una población blanca más humilde.

63 Ferrer, Germán, AO, 23 de mayo de 2008.

64 Estos postulados proceden del estudio de unos bancos de datos elaborados para cada sociedad con las diversas informaciones recogidas a lo largo de la investigación.

65 Para AO, se llegó a conocer la(s) profesión(es) de 163 socios, lo que corresponde a un $35 \%$ de los socios reportados en la base de datos. Para HM, se llegó a conocer la(s) profesión(es) 
co siguiente aparecen resumidas las principales categorías socioprofesionales presentes en cada institución ${ }^{66}$.

\section{CATEGORÍAS SOCIOPROFESIONALES DE LOS MIEMBROS DE LAS SOCIEDADES}

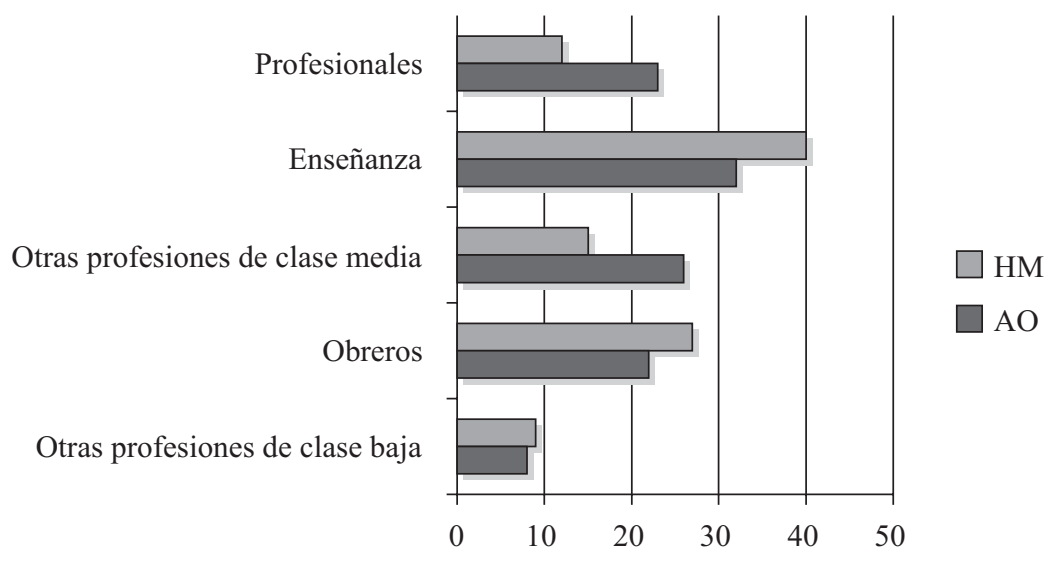

AO E HM:

En este gráfico se subrayó con un color más oscuro las profesiones que sugerían en la época un estatus social bastante alto, o mejor dicho cuyo valor era reconocido. Resulta significativo que en $\mathrm{AO}$, el porcentaje total de esas profesiones $(81 \%)$ resultaba más de dos veces superior al de las demás profesiones (de azul más claro), las cuales revelaban un menor nivel social (30\%). Por lo tanto, se desprende una posición social media entre la mayoría de los socios de AO cuyo oficio se llegó a conocer. En cuanto a la membresía de la Sociedad

de 42 socios, lo que equivale al $37 \%$ de los socios reportados en la base de datos. Pero hace falta precisar que el $21 \%$ de las profesiones conocidas para la Sociedad HM correspondían con socios que también eran de $\mathrm{AO}$, o que por lo menos eran visitantes de esta última sociedad.

66 En la categoría llamada «profesionales» se incluyó a los médicos, abogados y otros doctores (23\% para AO y $12 \%$ para $\mathrm{HM})$. La enseñanza era el sector de ocupación laboral del $32 \%$ de los socios de AO cuya profesión se pudo conocer, y del 40\% de los de HM. En las «otras profesiones de clase media» se abarcó a periodistas, procuradores, contadores, ingenieros, agrónomos, artistas, estudiantes o «preparados», propietarios industriales o terratenientes, y a militares o policías (26\% para AO y $15 \%$ para HM). Los «obreros» representaban los oficios de la construcción, de artes y técnicas, o del ramo del tabaco (22\% para AO y $27 \%$ para HM). Por fin, en las «otras profesiones de clase baja» se encontraban propietarios de pequeños comercios, empleados públicos, limpiabotas y conserjes (8\% para AO y $9 \%$ para $\mathrm{HM}$ ). 
HM, aparece como condición social más humilde en el gráfico. En las profesiones reportadas en la base de datos de HM, la diferencia se muestra menos marcada entre el porcentaje de profesiones de clase media (67\%) y el de las profesiones menos reconocidas socialmente (36\%). Además, se debe matizar la cifra de las profesiones de clase media por comprender una mayoría de maestros y maestras, de los cuales ya se señaló la situación laboral insegura.

La mayoría de los testimonios orales recogidos indicaron una disparidad de nivel social entre personas pertenecientes a $\mathrm{HM}$ y a $\mathrm{AO}$, y resulta interesante que a menudo iba acompañada por otro contraste basado en el color de la piel. La característica mulata destacada en socios importantes de AO, no sólo por su posición en la sociedad sino también por su posición fuera de ella, se contraponía con la característica negra atribuida a los socios de HM:

En Pinar del Río había dos sociedades, una de negros y una de mulatos ${ }^{67}$.

Se podrían citar numerosos testimonios, como el de Julieta Carrillo, quien distinguía la Sociedad AO, «de gente más bien mulata y educada», de la Sociedad HM, adonde «iba gente más prieta, más popular» ${ }^{68}$. Yolanda Gómez relacionaba el que $\mathrm{AO}$ «era bastante aristocrática» con el color de piel de sus miembros $^{69}$. En fin, las fuentes orales explicaron las tensiones entre ambos círculos por factores sociales, económicos y raciales. Margot Chirino Valdés, antigua socia de $\mathrm{AO}$, afirmó que entre blancos y negros existían dos prejuicios: racial y económico. En cuanto a Dioba Echevarría, antigua socia de HM, señaló que había discriminación dentro de la misma raza de color, de acuerdo con su posición social ${ }^{70}$.

Así pues, la Sociedad HM, a la cual «todo el mundo que tenía moral podía ir» ${ }^{71}$, era de acceso más libre que AO. Las bases de datos confirman la declaración de algunos entrevistados de haber participado en ambas asociaciones. En realidad, el caso más corriente era empezar en HM, y luego hacerse socio de AO, lo cual ya era indicador de cierto ascenso. Éste fue el caso de René Álvarez Soa, tabaquero, quien estuvo en HM hasta casarse en 1948 con una socia de AO, Hildelisa Puentes Fontayn, lo cual le permitió acceder a la otra socie$\operatorname{dad}^{72}$. No era raro ser «socio» de una sociedad y «visitante» de la otra, y las

67 Monterrey, «Mercedita», HM, 20 de marzo de 2008.

68 Carrillo, Julieta, AO, 23 de enero de 2008.

69 Gómez, Yolanda, AO, 10 de diciembre de 2007.

70 Ver las entrevistas con Yolanda Gómez, Sergio Llinás Carrillo, María Hernández, Emilia Viruliche, «Filo», Dioba Echevarría, «Mercedita», Esther Linares, y Ricardo Noriega.

71 Monterrey, «Mercedita», HM, 20 de marzo de 2008.

72 Álvarez Soa, René, HM y luego AO, 29 de enero de 2008. 
personas que habían pertenecido a HM siguieron visitándola aun después de ingresar en $\mathrm{AO}$, lo cual indicaba una apreciación distinta de las dos instituciones. Pero también había socios de HM que solían visitar AO, en particular para concurrir a sus bailes. En general, éstos habían alcanzado un nivel suficiente para ser reconocidos ocasionalmente entre la membresía de AO, ya fuera por su profesión, por su función en $\mathrm{HM}$, o por los lazos que mantuviesen con miembros de $\mathrm{AO}^{73}$.

El carácter bastante elitista que tenía $\mathrm{AO}$ a los ojos de la población negra local también se reflejaba en algunos de sus artículos, en los cuales se exponía una ambición, un deseo de superación y de progreso más pronunciados que en HM. En sus escritos, los redactores especificaban con qué medios la «progresista Sociedad Atenas Occidental» lograría «despertar los cerebros» ${ }^{74}$. El mero hecho de publicar su propia revista revelaba la presencia de intelectuales en AO, y constituía una fuente de difusión de sus méritos. La Sociedad AO desempeñaba un papel ennaltecedor para sus socios, conforme iba realzando su imagen social como institución en Pinar del Río. Del mismo modo que en la mayoría de las revistas o crónicas sobre sociedades blancas de la época, los periodistas de AO se esmeraban en subrayar las cualidades intelectuales y sociales de los demás socios. Su sed de reconocimiento social se expresaba con los mismos términos aduladores, como por ejemplo «el distinguido señor» o «el inteligente joven $»^{75}$. La insistencia sobre la belleza y la fineza abundó en los testimonios de personas que habían pertenecido a $\mathrm{AO}$ y quedó manifiesta en sus fotografías.

Además, las redes sociales fueron más desarrolladas (o fomentadas indirectamente a veces) por AO que por HM. Comparando las bases de datos correspondientes a cada una ${ }^{76}$, resulta obvio que los miembros de $\mathrm{AO}$ fueron los que más se comprometieron con otras actividades fuera de la sociedad, y su

73 Viruliche, Emilia, HM, 17 de marzo de 2008. Echevarría, Dioba, HM, 19 de marzo de 2008. Esta última, cuya madre era presidenta de HM, era aceptada de joven en fiestas de AO porque era acompañada por una mujer de AO que conocía a su familia.

${ }^{74}$ Las dos citas fueron extraídas respectivamente de Godoy, VI / 350 (Pinar del Río, 25 de julio de 1928), APPR. «¿Cuándo desaparecerán los prejuicios?», 2 (Pinar del Río, 15 de febrero de 1933): 3 .

75 Cuní, IV / 105 (Pinar del Río, 15 de julio de 1944).

76 He aquí los distintos elementos que se recogieron en los bancos de datos para cada socio (cuando fuera posible): apellido; nombre; sexo; función desempeñada en la sociedad; época de participación en la sociedad; participación en una revista, en la otra sociedad negra de Pinar del Río, en otras sociedades negras, en la FNSC; profesión; otras actividades relativas a la profesión; otros vínculos con la vida social local; participación en logias masónicas; compromiso político. 
acceso a diversos círculos sociales no era ni ajeno a su implicación en AO ni a su posición social ${ }^{77}$.

Ahora bien, las diferencias de estatus social también se advertían entre socios pertenecientes a una misma sociedad. Si tan sólo se consideraran los testimonios de antiguos socios, la mayoría de las veces embellecedores, podríamos pensar que todos los socios de AO tenían un nivel económico o social relativamente elevado. Sin embargo, es necesario distinguir la aspiración que se desprende de los testimonios orales y escritos de los socios, de la realidad social que se conoce gracias a la historiografía existente sobre la población cubana negra, y gracias al análisis comparativo de diferentes fuentes. Por lo que se refería a las profesiones ejercidas por los miembros de HM, se señalaba principalmente a obreros manuales, a maestros graduados o alumnos de la Escuela Normal, a muchachas «colocadas» (o sea que trabajaban de limpieza para otra casa que la suya), etc. En cambio, para AO se recordaba principalmente la presencia de profesionales. Algunos pocos entrevistados precisaron que en $\mathrm{AO}$ estaba representada la minoría de profesionales negros existentes en Pinar del Río. En realidad, en AO también había obreros de la construcción, y los profesionales no eran mayoritarios en la sociedad ${ }^{78}$. A menudo se subrayaba la preparación de los socios de AO, o el esfuerzo de superación que estaban realizando, y su refinamiento en la educación ${ }^{79}$. Se puede citar a Zoila Rubalcaba:

Había personas de gran valor, de gran prestigio, aunque fueran humildes [...] de mucho prestigio, preparados, aunque fueran campesinos ${ }^{80}$.

Por lo tanto, la distinción de AO no estribaba tanto en la riqueza de sus participantes, sino más bien en el título social y en el nivel cultural alcanzado por los mismos. Germán Ferrer y Lilia Pérez definían AO como la sociedad de los intelectuales ${ }^{81}$.

77 Las diferencias de nivel entre AO e HM se reflejan también en la distinta cantidad y variedad de información disponible para cada sociedad. De hecho, las actividades de HM eran menos difundidas públicamente.

78 Un antiguo socio directivo de AO (que antes había pertenecido a HM) y jefe de un taller de mecánica, matizó esa imagen idealizada recordando que entre la población negra era muy poco frecuente ser profesional. Ramírez, Manuel, HM y luego AO, 18 de marzo de 2008. Otro antiguo socio de $\mathrm{AO}$ y maestro precisó que en $\mathrm{AO}$ había más profesionales que en HM. «Filo», AO, 30 de abril de 2008.

79 Esther Linares, socia de HM de joven y conserje de AO en los años 1950 (junto a su marido Joaquín Molina), explicó el sentido que tenía entonces la expresión «ser de rango». Linares, Esther, 19 de mayo de 2008.

80 Rubalcaba, Zoila, AO, 18 de marzo de 2008.

81 Ferrer, Germán, AO, 23 de mayo de 2008. Pérez, Lilia, HM y AO, 3 de mayo de 2008. 
Luego, los entrevistados mencionaron en particular a unas personas que se destacaban del conjunto asociativo por sus méritos o fama, y que en cierta medida constituían unos modelos para los demás. René Álvarez, según el cual en $\mathrm{AO}$ «había personas que, dentro de la colectividad, sobresalían por sí», mencionaba por ejemplo a Regla Hernández y a Eusebio Contreras, quien «era una institución allíł» ${ }^{82}$. Además, las bases de datos evidencian que la multiplicación de actividades sociales se concentraba muchas veces en las mismas personas.

Por fin, cabe preguntarse qué individuos tuvieron mayores oportunidades para elevarse dentro de la institución, y si no había una correspondencia entre sus posiciones en ella y fuera de ella. Si bien la presencia de familias desempeñó un papel relevante en ambas sociedades negras de Pinar del Río, cobró una significación peculiar en AO, como lo sugería Dioba Echevarría Gutiérrez al decir que «Atenas Occidental era más bien por los apellidos» ${ }^{83}$. Resulta significativo el hecho de que sobre las 43 familias de AO consideradas como dominantes por el número de miembros que abarcaban, sólo 4 de ellas no comprendían a ningún socio directivo. Así pues, la importancia de las familias no sólo radicaba en el peso numérico de sus componentes en la asociación. Según Rosa Ramírez, eran los profesionales quienes sostenían $\mathrm{AO}^{84}$. Elaborando tablas que agrupan informaciones sobre el apellido, la función dentro de la sociedad y la profesión de cada socio, se comprobó que muchas veces la función directiva de una persona en $\mathrm{AO}$ se conjugaba con el ejercicio de una profesión de renombre y funciones sociales destacables. En la Sociedad HM, a pesar de que el fenómeno fuera menor que en AO, se puede citar el ejemplo de Saúl Menéndez, quien era maestro, masón, y presidente de $\mathrm{HM}^{85}$.

Si bien pertenecer a una sociedad reconocida ayudaba a construir redes sociales fuera de ella, también era verdad lo contrario, es decir que el nivel social alcanzado por las personas era una ventaja para entrar en la sociedad y lograr buen lugar dentro de ella. Por lo tanto, la jerarquía interna existente en las sociedades negras pinareñas reflejaba sin duda unas disparidades dentro de la propia comunidad negra de la ciudad, y determinaba una diferencia de oportunidades para la integración social de sus miembros.

En conclusión, el análisis de las Sociedades AO e HM, próximas en numerosos aspectos a las demás organizaciones de ese tipo, permite entender cuáles

82 Álvarez Soa, René, HM y luego AO, 29 de enero de 2008.

83 Echevarría, Dioba, HM, 19 de marzo de 2008.

84 Ramírez, Rosa, AO, 1ro de mayo de 2008.

85 Libreta del directorio de 1964 de la Logia Paz y Concordia. Entrevistas ya citadas con Julieta Carrillo y con Rosa Ramírez. Es notable el parentesco existente entre Saúl, Julieta y Rosa, siendo estas últimas antiguas socias de AO. 
fueron sus diferentes funciones en la Cuba republicana. Fundadas en reacción a la discriminación sufrida por la población negra, estas dos asociaciones pinareñas no optaron nunca por una lucha separada del resto de la sociedad, sino que al contrario constituyeron para sus miembros unos importantes mecanismos de integración en la nación cubana.

Ahora bien, los grandes cambios políticos de la era republicana no acarrearon una franca ruptura con el pasado colonial, y los prejuicios que vinculaban a los negros con una condición social y cultural pobre persistieron. En consecuencia, aunque las Sociedades AO e HM lucharon por superarlos, no pudieron eludirlos en su búsqueda de reconocimiento. Paradójicamente, su integración en la nación significaba abrazar un imaginario que, tras apariencias de igualdad y de unión, llevaba el sello de la exclusión y de la aculturación para los descendientes de esclavos africanos. Desde luego, su integración total en el país implicaba una aceptación de su estructura social. Para ser reconocidos por la sociedad cubana influyente, los miembros de AO y de HM intentaron destacarse del conjunto poblacional negro rechazando su herencia cultural y tratando de ascender socialmente. Por consiguiente, reprodujeron en cierta medida unos mecanismos excluyentes y elitistas para llegar a sus fines. Fueron organismos representantes de las crecientes desigualdades entre los afrocubanos, y a la vez generadores de esa heterogeneidad por continuar alimentando las diferencias sociales y raciales entre ellos.

Por último, el análisis de las desemejanzas entre AO e HM revela que esa heterogeneidad también estaba jerarquizada. La Sociedad AO, de mayor nivel y más empeñada en sobresalir en el escenario social pinareño, había alcanzado un mayor prestigio que la Sociedad HM. Resulta evocadora la referencia de Sergio Llinás Carrillo a las ambiciones de AO («la Atenas») y de HM («la Maceo»):

La Maceo era llegar hasta donde llegó la Atenas, y la Atenas llegar hasta donde llegó la de blancos ${ }^{86}$.

De hecho, ambas asociaciones fueron portavoces de sectores sociales diferentes no sólo por su nivel de vida, sino también por sus objetivos y posiciones ideológicas. Finalmente, la heterogeneización y jerarquización que fomentaron en la población negra pinareña reflejaba en pequeña escala la propia organización social de Cuba, revelando un importante grado de integración en ella. Por ello, será enriquecedor aplicar semejantes métodos investigativos al análisis de

86 Llinás Carrillo, Sergio, 23 de enero de 2008. El autor de la cita es hijo de Julieta Carrillo, quien había pertenecido primero a la Sociedad El Porvenir en Consolación del Sur, y luego a AO en Pinar del Río; y de Sergio Llinás Quintáns, secretario de AO durante muchos años e hijo de un fundador de la sociedad. 
sociedades homólogas de la parte occidental de la isla, tomando en cuenta tanto el papel referencial de La Habana, como las diferencias de entorno histórico-regional de cada una. Por fin, este análisis comparativo seguirá nutriendo las vastas reflexiones sobre las relaciones raciales y sociales en la República cubana, y sobre la identificación de los ciudadanos negros con una cultura nacional, que si bien fue evolucionando durante ese período, permaneció teñida de un imaginario a su vez muy marcado por el ideario de los tiempos coloniales.

\section{BIBLIOGRAFÍA:}

Atalaya: Órgano de Orientación, Cultura y Publicidad («periódico quincenal editado por la Sección Juvenil de la Sociedad Atenas Occidental»), Pinar del Río, I / 3 (22 de abril de 1942); I / 4 (10 de mayo de 194), fotocopias facilitadas por María Elena Camero.

Atenas: Revista mensual ilustrada de afirmación cubana (órgano oficial del Club Atenas), La Habana, 1-24 (1920-1921).

«Atenas Occidental celebró el XXIX aniversario de su fundación con una gran velada», Heraldo Pinareño, XXVI / 1990 (Pinar del Río, 26 de marzo de 1949).

Barcia, María del Carmen, Capas populares y modernidad en Cuba (1878-1930), La Habana, La Fuente Viva, 2005.

Barcia Paz, Manuel, La resistencia esclava en las plantaciones cubanas (1790-1870), Pinar del Río, Ediciones Vitral, 1998.

Batuala: Revista Quincenal, Pinar del Río, 2 (15 de febrero de 1933).

Casanovas Codina, Joan, ; O pan, o plomo! Los trabajos urbanos y el colonialismo español en Cuba, 1850-1898, Madrid, Siglo Veintiuno de España Editores, 2000 (1ra ed. en inglés: 1998).

«¿Cuándo desaparecerán los prejuicios?», Batuala: Revista Quincenal, 2 (Pinar del Río, 15 de febrero de 1933): 3.

« 42.000 distribuyó la renta de Lotería Nacional. Distintas sociedades e instituciones fueron beneficiadas», La Tarde, X / 410 (Pinar del Río, 3 de marzo de 1951), BPPR.

Cuní, Ramón, «Nuevos graduados», Vocero Occidental, IV / 105 (Pinar del Río, 15 de julio de 1944).

«Del Presidente de «Atenas Occidental» a nuestro director», Heraldo Pinareño, XVI / 959 (Pinar del Río, 4 de enero de 1938): 1.

«Ecos de un homenaje», Vocero Occidental (Pinar del Río, junio de 1946): 3 y 6.

Espina Prieto, Rodrigo y Rodríguez Ruiz, Pablo, «Raza y desigualdad en la Cuba actual», Temas: cultura, ideología, sociedad, 45 (La Habana, enero-marzo de 2006): 45. 
Evolución: Revista Mensual Ilustrada, Pinar del Río, II / 9 (octubre de 1924).

Ferrer, Ada, «Cuba insurgente. Raza, nación y revolución, 1868-1898», Caminos: Revista Cubana de Pensamiento Socioteológico, 24-25 (La Habana, 2002): 19-34.

Franco, José Luciano, La conspiración de Aponte. 1812, La Habana, Editorial de Ciencias Sociales, 2006 (1ra ed. 1963).

Fuente, Alejandro (de la), Una nación para todos. Raza, desigualdad y política en Cuba. 1900-2000, Madrid, Editorial Colibrí, 2000.

García, Gloria, Conspiraciones y revueltas. La actividad política de los negros en Cuba (1790-1845), Santiago de Cuba, Editorial Oriente, 2003.

García, Gloria, «Los cabildos de nación: organización, viscitudes y tensiones internas (1780-1868)», Del Caribe, 43 (Santiago de Cuba, 2004): 65-73.

Godoy, Ricardo, «Espléndida romería», Heraldo Pinareño, VI / 350 (Pinar del Río, 25 de julio de 1928).

González Ripoll, María Dolores, Naranjo, Consuelo, Ferrer, Ada, García, Gloria y Opatrny, Josef, El rumor de Haití en Cuba: temor, raza y rebeldía, 1789-1844, Madrid, CSIC, 2004.

Helg, Aline, Lo que nos corresponde: la lucha de los negros y mulatos por la igualdad en Cuba. 1866-1912, La Habana, Imagen Contemporánea, 2000 (1. a ed. 1995 en inglés).

Heraldo Pinareño (o Heraldo de Occidente), Pinar del Río (1927, 1928, 1936-1940, 1945, 1946, 1949-1951, 1953).

Herrera Quintáns, Alfredo, «Capitalismo, racismo y patriotismo», Batuala: Revista Quincenal, 2 (Pinar del Río, 15 de febrero de 1933): 8.

«La Convención de Sociedades de Color», Mediodía, III / 55 (La Habana, 14 de febrero de 1938): 13.

Hevia Lanier, Oílda, El Directorio Central de las Sociedades Negras de Cuba, 1886-1894, La Habana, Editorial de Ciencias Sociales, 1996.

«La visita del presidente de la República a esta ciudad constituirá un acontecimiento. El programa de los festejos», Heraldo Pinareño, V / 276 (Pinar del Río, 24 de marzo de 1927): 1.

Le Riverend Brusone, Julio, Historia ecomómica de Cuba, La Habana, Ciencias Sociales, 1985.

«Los actos del día 24 de febrero», Heraldo Pinareño, V / 267 (Pinar del Río, 26 de febrero de 1927): portada.

Martí, José, «Nuestra América», El Partido Liberal, (México, 30 de enero de 1891), Obras completas, T6, La Habana, Editorial de Ciencias Sociales, 1975: 15-23. 
Montejo Arrachea, Carmen V., Sociedades negras en Cuba, 1878-1960, La Habana, Editorial de Ciencias Sociales, 2004.

Naranjo Orovio, Consuelo, «Hacia una sociedad moderna: inmigración y blanqueamiento», Del Caribe, 25 (Santiago de Cuba, 1996): 54-62.

Naranjo Orovio, Consuelo, «Cuba, 1898: Reflexiones en torno a los imaginarios nacionales y a la continuidad», Cuadernos de Historia Contemporánea, 20 (Madrid, 1998): 231-232.

Naranjo Orovio, Consuelo, «Cultura, identidad y nación en las obras de Fernando Ortiz y Antonio S. Pedreira», Tebeto: anuario del archivo histórico insular de Fuerteventura, Extra 5 (2004).

Naranjo Orovio, Consuelo, «De la esclavitud a la criminalización de un grupo: la población de color en Cuba», Op. cit., 16 (Río Piedras, Puerto Rico, 2005): 137-179.

Naranjo Orovio, Consuelo, «El peso de la esclavitud en Cuba: miedo y recelos contra una población», Ibero-americana Pragensia - Supplementum, Pensamiento Caribeño. Siglos XIX y XX, 19 (Praga, 2007): 313-325.

Naranjo Orovio, Consuelo y Puig-Samper Mulero, Miguel Ángel, «Fernando Ortiz y las relaciones científicas hispano-cubanas, 1900-1940», Revista de Indias, LX / 219 (Madrid, 2000): 477-503.

Naranjo Orovio, Consuelo y Puig-Samper Mulero, Miguel Angel, «Delincuencia y racismo en Cuba: Israel Castellanos versus Fernando Ortiz», Catauro, VII / 13 (La Habana, 2006): 53-66.

Ortiz, Fernando, Hampa Afro-Cubana: los negros esclavos, La Habana, Imprenta La Universal, 1916.

Ortiz, Fernando, El engaño de las razas, La Habana, Ciencias Sociales, 1975 (1ra ed. 1945).

Ortiz García, Carmen, «Cultura popular y construcción nacional: la institucionalización de los estudios de folklore en Cuba», Revista de Indias, LXIII / 229 (Madrid, 2003): 695-736.

Pichardo Viñals, Hortensia, Documentos para la historia de Cuba, La Habana, Editorial de Ciencias Sociales, Instituto Cubano del libro, 1971 (1ra ed. 1969).

Pinar del Río: Órgano oficial del Comité «Todo por Pinar del Río», (1949, 1950), BNJM; (1947, 1948, mayo-octubre 1950).

Portuondo Linares, Serafín, Los independientes de color. Historia del Partido Independiente de Color, La Habana, Editorial Caminos, 2002 (1ra ed. 1950).

Pozo, Victorino F., «Renovarse o morir», Evolución: Revista Mensual Ilustrada, II / 9 (Pinar del Río, octubre de 1924): 8.

Puig-Samper, Miguel Ángel y Naranjo Orovio, Consuelo, «Fernando Ortiz: herencias culturales y forja de la nacionalidad», Naranjo Orovio, Consuelo y Serrano, Carlos 
(Eds.), Imágenes e imaginarios nacionales en el ultramar español, Madrid, CSIC-Casa de Velázquez, 1999: 197-226.

Reglamento de la Sociedad «Hijos de Maceo», Pinar del Río, Imp. «La Comercial», 17 de octubre de 1952, facilitado por Santos Carrete Galán.

Renan, Ernest, Qu'est-ce qu'une nation?, Paris, Le Mot et le Reste, 2007 (1ère éd. 1882).

Scott, Rebecca J., La emancipación de los esclavos en Cuba: la transición al trabajo libre, 1860-1899, La Habana, Editorial Caminos, 2001 (1ra ed. 1986 en inglés).

Soucy, Dominique, Masonería y nación. Redes masónicas y políticas en la construcción identitaria cubana (1811-1902), Santa Cruz de Tenerife, Ediciones Idea, 2006.

Tocqueville, Alexis (de), De la démocratie en Amérique, Paris, Éditions de Vrin, 1990.

Vocero Occidental, Pinar del Río, 1- 60 (mayo de 1941- abril de 1943), (1955 y 1956), APPR; (1943-1952, 1955, 1956, 1959).

\section{ENTREVISTAS:}

Álvarez Soa, René, HM y AO, Pinar del Río, 29 de enero de 2008 (grabación y transcripción).

Carrete Galán, Hilda, AO, Pinar del Río, 22 de mayo de 2008 (transcripción).

Carrete Galán, Santos y Pérez, Lilia, HM y AO, Pinar del Río, 3 y 20 de mayo de 2008 (grabación y transcripción).

Carrillo, Julieta y Llinás Carrillo, Sergio (su hijo), AO, La Habana, 2 de diciembre de 2007 (transcripción), 23 de enero de 2008 (grabación y transcripción) y mayo de 2008 (transcripción).

Echevarría Gutiérrez, Dioba, HM, Pinar del Río, 19 de marzo de 2008 (grabación y transcripción).

Ferrer Casanova, Justo Germán, AO, Pinar del Río, 23 de mayo de 2008 (transcripción).

Gómez, Yolanda, AO, Pinar del Río, 10 de diciembre de 2007 (grabación y transcripción).

Hernández Hernández, María y Cárdenas Hernández, Aleida (su hija), AO, Pinar del Río, 28 de enero (grabación y transcripción), 17 de marzo y 19 de mayo de 2008 (transcripciones).

Linares Estevez, Esther, HM (y conserje de AO), Pinar del Río, 19 de mayo de 2008 (grabación y transcripción).

López, Julio, AO, Pinar del Río, 30 de abril (con la presencia de «Filo») y 3 de mayo de 2008 (transcripciones).

Monterrey Hernández, Mercedes («Mercedita»), HM, Pinar del Río, 20 de marzo de 2008 (grabación y transcripción). 
Noriega, Ricardo, AO, Pinar del Río, 16 de noviembre de 2007 y 29 de abril de 2008 (transcripciones).

Ramírez, Manuel (con la presencia de su hermano Juan Akim Ramírez en la primera entrevista), HM y AO, Pinar del Río, 29 de enero (transcripción) y 18 de marzo de 2008 (grabación y transcripción).

Ramírez, Rosa, AO, Pinar del Río, 1ro de mayo de 2008 (grabación y transcripción).

Rubalcaba, Zoila, AO, Pinar del Río, 17 (grabación y transcripción) y 20 de marzo de 2008 (transcripción).

Valdés, Amparo («La Chinita») y Chirino Valdés, Margot (su hija) (con la presencia de «Filo» en la primera entrevista), HM y AO, Pinar del Río, 19 y 21 de marzo de 2008 (transcripciones).

Vázquez Rodríguez, Gilberto («Filo»), AO, Pinar del Río, 18 de marzo y 30 de abril de 2008 (transcripciones).

Viruliche, Emilia, HM, Pinar del Río, 29 de enero (grabación y transcripción) y 17 de marzo de 2008 (transcripción).

Fecha de recepción: 9-2-2010

Fecha de aceptación: 8-9-2010

\section{BLACK INVOLVEMENT IN ASSOCIATIONS IN CUBA: A MEANS OF INTEGRATING INTO THE REPUBLICAN SOCIETY (1920-1960)}

In newly independent Cuba, black associations began to acquire specific functions within the new republican context of the first half of the 20th century. Starting with an analysis of two black societies of education and recreation in the city of Pinar del Rio, the article shows their importance as platforms for the social integration of their members. Nevertheless this goal, in keeping with the national narrative then under construction, signified the continuation of the process of acculturation and the heterogeneity of the black population. Finally, these two socializing spaces were mirror images of the prevailing hierarchical system in Cuba.

KEY WORDS: Republic of Cuba, black associations, exclusion and integration, acculturation, national narrative. 